\title{
Mallory-Weiss sendromunda tanı, klinik seyir ve endoskopik tedavi
}

\author{
Diagnosis, clinical course, and endoscopic therapy in Mallory-Weiss syndrome
}

Muhammet Yener AKPINAR ${ }^{1}$, Zeki Mesut Yalın KILIÇ², Erkin ÖZTAŞ³ , Volkan GÖKBULUT², İsmail Hakkı KALKAN², Meral AKDOĞAN KAYHAN ${ }^{2}$, Sabite KAÇAR ${ }^{2}$, Hale GÖKCAN ${ }^{2}$, Yasemin ÖZDERIN ÖZİN ${ }^{2}$, Ertuğrul KAYAÇETIN ${ }^{2}$

Keçiören Eğitim ve Araştırma Hastanesi, ${ }^{1}$ Gastroenteroloji Kliniği, Ankara

Türkiye Yüksek Thtisas Eğitim ve Araşttrma Hastanesi, ${ }^{2}$ Gastroenteroloji Kliniği, Ankara

Eskişehir Osmangazi Universitesi Tip Fakültesi, ${ }^{3}$ Gastroenteroloji Bilim Dal, Eskişehir

Giriş ve Amaç: Mallory-Weiss sendromu üst gastrointestinal sistem kanamalarının \%1-4 kadarından sorumludur. Çoğu Mallory-Weiss sendromu spesifik endoskopik tedavi gerektirmeyen bir şekilde hafif kanama ile seyreder; bununla beraber bazı olgularda kanama abondan olabilir. Ülser kanamalarından farklı olarak Mallory-Weiss sendromunda endoskopik tedavi çok iyi standartize edilmemiştir. Biz bu çalışmamızda kendi olgularımızın demografik özelliklerini, uygulanılan endoskopik tedavileri ve hastaların klinik seyirlerini karşılaştırmayı hedefledik. Gereç ve Yöntem: Türkiye Yüksek Ihtisas Eğitim ve Araştırma Hastanesi, Endoskopi ünitesinde 2010-2017 tarihleri arasında Mallory-Weiss sendromu tanısı almış hastalar retrospektif olarak incelendi. Bulgular: Çalışmaya toplam 37 hasta (erkek/kadın: 29/8,

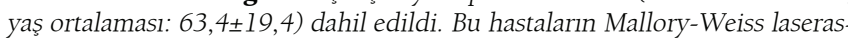
yonu endoskopi esnasında oluşan hasta sayısı 15 olup hastaların 27 tanesinde aktif kanama belirtisi vardi. Primer hemostaz 25 hastada \%92,5 siklıkta izlendi. Aktif kanama belirtisi olan hastalara uygulanılan endoskopik tedaviler adrenalin enjeksiyonu, klips uygulaması, heater prob idi. Mallory-Weiss sendromu oluşumuna göre hastalar iatrojenik Mallory-Weiss sendromu olan ve olmayan hastalar olarak iki gruba ayrıldı. Hastanede yatış varlığı, eritrosit süspansiyonu verilme ihtiyacı, aktif kanama belirtisi varlığı, hiatal herni varlığı ve uygulanılan endoskopik tedaviler karşılaştırıldığında bu parametreler açısından gruplar arasında fark yoktu. Toplam 27 hastaya klips uygulaması yapılmıştı; bu hastaların 19 tanesine sadece klips uygulanırken 8 tanesine ise klips ile beraber adrenalin uygulaması yapıldı. Hastalarımızda Mortalite izlenmedi. Sonuç: Mallory-Weiss sendromlu çoğu hasta klinik olarak benign seyir gösterse de bu hastaların şiddetli kanama ile beraber olacakları akılda tutulmalıdır. Hemoklipsler tedavide etkin ve güvenli bir endoskopik tedavi yöntemidir.

Anahtar kelimeler: Endoskopi, gastrointestinal sistem kanaması, Mallory-Weis sendromu
Background and Aims: Mallory-Weiss syndrome is responsible for upper gastrointestinal bleeding with a 1\%-4\% frequency. Most patients with Mallory-Weiss syndrome have a clinically mild course and do not require specific endoscopic treatment. However, some patients with Mallory-Weiss syndrome have severe bleeding. Endoscopic treatment of Mallory-Weiss syndrome is not standardized when compared with that of bleeding ulcers. Here we aim to share our patients' demographic properties, applied endoscopic treatments, and clinical courses of patients. Materials and Methods: We researched our patients with Mallory-Weiss syndrome in Türkiye Yüksek Ihtisas Training and Research Hospital Endoscopic Unit between 2010 and 2017. Results: Overall, 37 patients (males/females: 29/8, mean age: $63.4 \pm 19.4$ years) were included in the study. Mallory-Weiss syndrome occurred in 15 patients in whom routine endoscopic procedures were performed. Stigmata of active bleeding were observed in 27 patients. Primary hemostasis was achieved in 25 patients with $92.5 \%$ frequency. Endoscopic procedures including placement of hemoclips, injection of epinephrine, and thermocoagulation with a heater probe were performed in patients with stigmata of active bleeding. Patients were divided into two groups depending on whether the origin of Mallory-Weiss syndrome was iatrogenic. Hospital stays, erythrocyte transfusion rates, primary hemostasis, stigmata of active bleeding, and frequencies of hiatal hernia were compared between the two groups. There were no differences between the two groups. Placement of hemoclips was performed in 27 patients; 19 patients received hemoclips alone whereas 8 patients received hemoclips with epinephrine injections. Mortality was not observed in any of our patients. Conclusion: Although most patients with Mallory-Weiss syndrome have benign clinical courses, it is important to keep in mind that Mallory-Weiss syndrome can be associated with severe bleeding. Hemoclip placement is an effective endoscopic treatment method in Mallory-Weiss syndrome.

Key words: Endoscopy, gastrointestinal system bleeding, Mallory-Weiss syndrome

madde enjeksiyonu, hemoklip uygulaması, heater prob ile koagülasyon, argon plazma koagülasyonu, endoskopik bant ligasyonu) başarı ile uygulanmıştır $(3,4)$.

Peptik ülser, eroziv mukozal hasar ve varis kanamaları üst gastrointestinal sistem kanamalarının en sık nedenlerini oluşturmaktadır. Son yıllarda yapılan çalışmalarla bu hastalıklara yaklaşım ve uygulanması gereken endoskopik tedaviler daha standartize hale gelmiştir. Bununla beraber üst GIS kanamasının daha az sıklıkta görülen etiyolojileri için ise yukarda adı geçen nedenlere kıyasla daha az çalışma yapılmış olup uygu- 
lanması gereken endoskopik tedaviler açısından belli bir fikir birliği yoktur. Biz bu çalışmamızla hastanemizde MWS tanısı konulan hastaların demografik özelliklerini, klinik seyirlerini ve uygulanılan endoskopik tedavileri derleyerek kendi klinik deneyimimizi ortaya koymayı hedefledik.

\section{GEREC ve YÖNTEM}

\section{Çalışma Dizaynı ve Hastalar}

Çalışma retrospektif olarak dizayn edilmiştir. Türkiye Yüksek Ihtisas Eğitim ve Araştırma Hastanesi Endoskopi Ünitesinde 2010-2017 tarihleri arasında üst GIS endoskopisi yapılan hastalar taranmıştır. Endoskopi raporunda MWS ibaresi olan hastalar çalışmaya alınmıştır.

\section{Tanımlamalar ve Endoskopik İşlemler}

Gastrointestinal sistem kanaması ile başvuran tüm hastalarda üst GIS endoskopisi ilk başvurudan itibaren 12 saat içinde yapıldı. MW laserasyonu gastroözofageal bileşke hizasında yerleşik yırtık olarak tanımlandı (Resim 1). Endoskopik tedavi laserasyondan endoskopi esnasında görülen kanama, damar ve/veya laserasyonun üzerine oturmuş pihtı varsa uygulandı. Primer hemostaz ilk endoskopide kanamanın durdurulması olarak tanımlandı. Tüm endoskopik işlemler GIS kanaması tanı ve tedavisi konusunda deneyimi yüksek endoskopistler tarafından yapıldı. Endoskopik işlemlerde ön görüşlü endoskop (Olympus Medical Systems, Tokyo, Japan) kullanıldı. Dilüe adrenalin injeksiyonu için $0,5 \mathrm{ml}$ adrenalin ampulu 20 cc enjektöre \%0,9 NaCl ile dilüe edilerek hazırlandı. Hangi endoskopik tedavinin uygulanacağı o esnada işlemi yapan endoskopist tarafından belirlendi. Hemoklips (Microvasive, Boston Scientific Corp, Massachusetts, US) laserasyonun her iki tarafını tutacak şekilde uygulandı (Resim 2). Olympus Heater prob ile lezyon koagüle edilmeye çalışıldı.

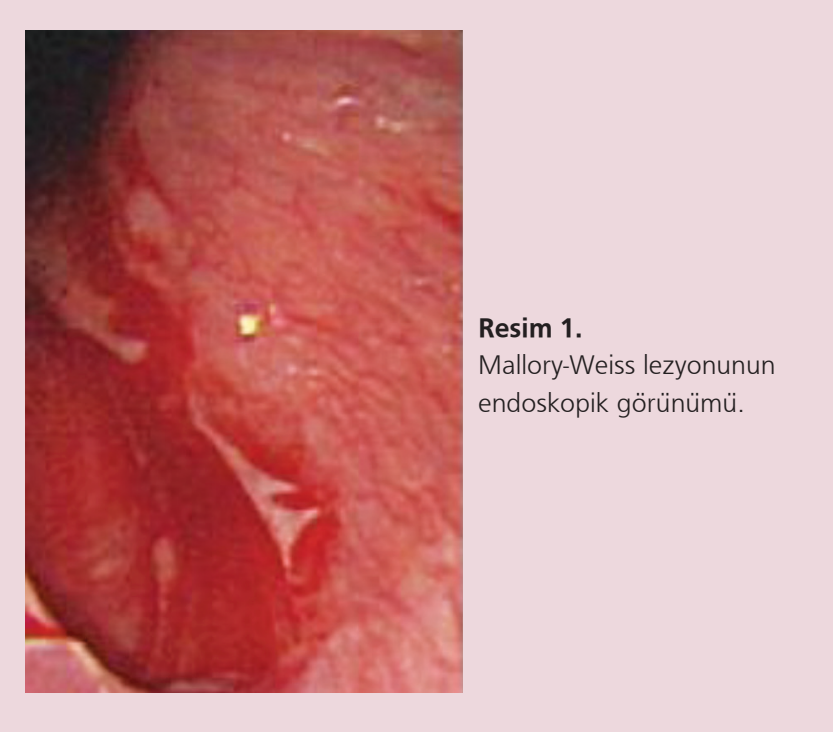

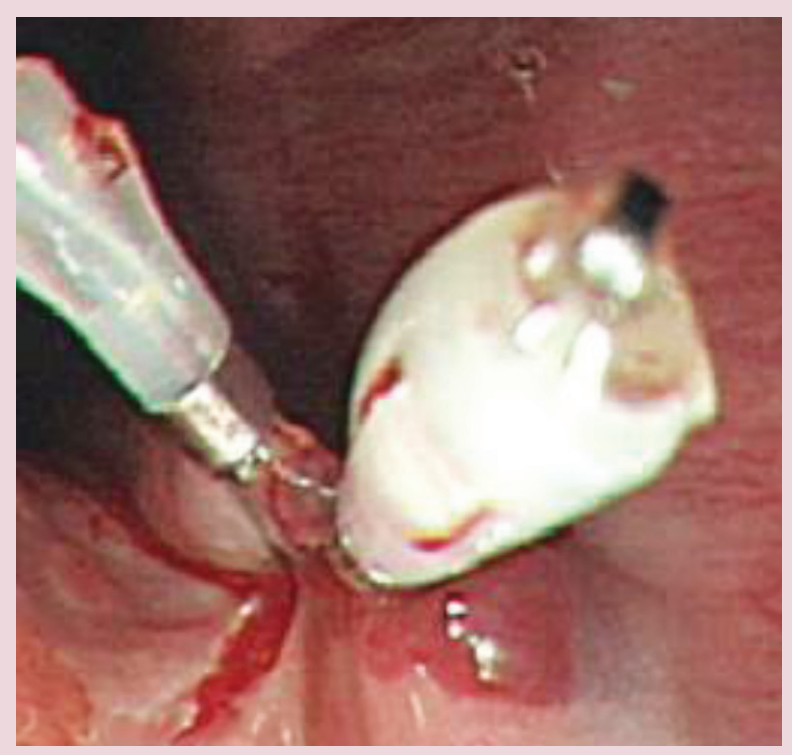

Resim 2. Mallory-Weiss sendromunun endoskopik tedavisinde kullanılan klipsler. Lezyonun klipsler ile kapatıldığı görülmektedir.

\section{Çalışma Verileri}

Çalışma verisi olarak hastaların; endoskopik özellikleri, MW laserasyonunun üst GIS endoskopisi esnasında oluşup oluşmadığı, hastaneye başvuruları esnasında yapılan kan tahlilleri, hastanede yatış durumları, yatmışlarsa hastanede yatış süreleri, bu sürede eritrosit transfüzyonu alıp almadıklanı incelenmiştir. Endoskopik özellikler içinde MW laserasyonu sayısı, uzunluğu, mideye uzanımının olup olmadığı, hiatal herni varlığı, eşlik eden endoskopik tanıları, MWS için uygulanılan endoskopik tedavileri, kaç tane endoskopik seansa gereksinim duyulduğu ayrıntılı olarak incelenmiştir.

Çalışmaya alınan hastalar MW laserasyonunun oluşma durumuna göre iki gruba ayrıldı. Ilk grup GIS kanama ile başvuran ve endoskopilerinde MWS tanısı konulan hastalardan oluşurken ikinci grup farklı endikasyonlarla üst GIS endoskopisi yapılan ve işlem esnasında MW laserasyonu gelişen hasta grubundan oluşmaktaydı. Bu iki grup arasında hastanede yatış ihtiyacı, eritrosit transfüzyonu ihtiyacı, aktif kanama, uygulanılan endoskopik tedaviler, MW laserasyonunun morfolojik özellikleri ve hiatal herni varlığı gibi değişkenler karşılaştırıldı.

\section{İstatistik}

Sürekli değişkenleri tanımlamak için deskriptif istatistikler kullanılmıştır (ortalama, standart sapma, minimum, medyan, maksimum). Bağımsız ve normal dağılıma uygunluk gösteren iki değişkenin karşılaştırması Student t-testi ile yapılmıştır. Bağımsız ve normal dağılıma uygunluk göstermeyen iki değişkenin karşılaştırması Mann-Whitney U testi ile yapılmıştır. Kategorik değişkenler arasındaki ilişkinin incelenmesi amacryla Ki-Kare (ya da uygun yerlerde Fisher Exact test) kulla- 
nılacaktır. Istatistiksel anlamlılık düzeyi 0,05 olarak belirlenmiștir. Analizler MedCalc Statistical Software version 12.7.7 (MedCalc Software bvba, Ostend, Belgium; http://www.medcalc.org; 2013) Programı kullanılarak gerçekleştirilmiştir.

\section{Etik Kurul}

Bu çalışma Türkiye Yüksek thtisas Eğitim ve Araştırma Hastanesi Eğitim ve Planlama ve Koordinasyon Kurulu Onayı alınarak yapilmıştır.

\section{BULGULAR}

Verileri sağlıklı olan toplam 37 hasta çalışmaya dahil edildi. Hastaların 29 tanesi erkek ve 8 tanesi kadın olup yaş ortalaması 63,4 $\pm 19,4$ olarak bulundu. Hastaların 22 tanesinde MWS tanısı GIS kanama ile başvuran hastalarda yapılan endoskopi ile konulurken geri kalan 15 hastada MWS farklı nedenlerle yapilan endoskopik işlemlerde oluştu. Hastalara ortalama $1,2 \pm 0,5$ endoskopik işlem uygulandı. 27 hastada aktif kanama bulgusu izlendi (\%73). Primer hemostaz oranı \%92,5 olarak bulundu. 13 hasta $(\% 35,1)$ hastaneye yatırlarak tedavi edilirken geri kalan 24 hasta $(\% 64,9)$ ayaktan takip edildi. Hastaların ortalama yatış süresi $6,3 \pm 3,7$ olarak bulundu. Toplamda 2 hastaya eritrosit transfüzyonu yapildı. Tedavi ve takip edilen hiçbir hastada mortalite gerçekleşmedi (Tablo 1).

Tablo 1. Hastaların demografik verileri, hastanede yatış özellikleri, primer hemostaz oranı ve ilk başvurudaki laboratuvar değerleri

\begin{tabular}{|c|c|}
\hline Değişken & Sayı \\
\hline Hasta sayısı & 37 \\
\hline Yaş (ortalama) & $63,4 \pm 19,4$ \\
\hline Cinsiyet (erkek/kadın) & $29 / 8$ \\
\hline \multicolumn{2}{|l|}{ Mallory-Weiss sendromu } \\
\hline Endoskopi esnasında oluşan MW lezyonu & $15(\% 40,5)$ \\
\hline MWS'na bağlı GIS kanama ile başvuru & $22(\% 59,5)$ \\
\hline Aktif kanama bulgusu olan hasta & $27(\% 73)$ \\
\hline Primer hemostaz oranı & $25 / 27(\% 92,5)$ \\
\hline Endoskopi seansı (ortalama) & $1,2 \pm 0,5$ \\
\hline Hastaneye yatan hasta & $13(\% 35,1)$ \\
\hline Yatış Süresi (ortalama-gün) & $6,3 \pm 3,7$ \\
\hline Eritrosit transfüzyonu yapılan hasta & $2(\% 5,6)$ \\
\hline Hemoglobin (ortalama) gr/dl & $12,7 \pm 2,3$ \\
\hline Platelet (ortalama) & $244521,7 \pm 53283$ \\
\hline INR (ortalama) & $1,6 \pm 1$ \\
\hline Üre (ortalama) & $58,7 \pm 34,3$ \\
\hline Kreatinin (ortalama) & $0,9 \pm 0,2$ \\
\hline
\end{tabular}

MW: Mallory-Weiss lezyonu. MWS: Mallory-Weiss Sendromu. GIS: Gastrointestinal sistem. INR: Uluslararası normalleștirilmiş oran.
Tablo 2. Hastaların endoskopik özellikleri ve uygulanan tedaviler

\begin{tabular}{ll} 
Değişken & Sayı \\
MW lezyonu boyutu (ortalama-mm) & $8,4 \pm 3,7$ \\
MW lezyonu sayısı (ortalama) & $1,3 \pm 0,7$ \\
MW lezyonu mideye uzanımı & $7(\% 18,9)$ \\
Hiatal Herni varlığı & $5(\% 13,5)$ \\
Ilave endoskopik tanılar & \\
Gastrit & 20 \\
Gastrik ülser & 6 \\
Duodenal ülser & 3 \\
Eroziv gastrit & 5 \\
Özofajit & 2 \\
Gastrik kanser & 1 \\
Uygulanan endoskopik tedaviler & \\
\hline Hemoklips uygulaması & $27(\% 100)$ \\
Adrenalin enjeksiyonu & $8(\% 29,6)$ \\
Heater prob ile koagülasyon & $4(\% 14,8)$ \\
Uygulanan hemoklips sayısı (ortalama) & $3,07 \pm 1,6$ \\
\hline
\end{tabular}
MW: Mallory-Weiss.

Mallory-Weiss lezyonu ortalama uzunluğu 8,4 $\pm 3,7 \mathrm{~mm}$ olup MW lezyon sayısı hastalarda 1 ile 4 arasında değişmekteydi (ortalama 1,3 $\pm 0,7)$. MW lezyonu 7 hastada $(\% 18,9)$ mideye uzanım göstermekteydi. Ilave endoskopik bulgulara bakıldığ zaman hiatal herni sıklığı hastalarımızda \%13,5 (5 hasta) olarak izlendi. Hastalarımızdaki ilave endoskopik tanılar ise sıklık sırasına göre şöyleydi: Gastrit (20 hasta), gastrik ülser (6 hasta), duodenal ülser (3 hasta), eroziv gastrit (5 hasta), özofajit (2 hasta), gastrik kanser (1 hasta). Hastalarımıza uygulanan endoskopik tedaviler adrenalin enjeksiyonu, hemoklips uygulaması ve heater prob ile koagülasyondan oluşmaktaydı. En sık uygulanan tedavi yöntemi 27 hastaya olmak üzere hemoklips yöntemiydi. Bu hastaların 19 tanesinde hemoklips tek başına uygulanırken geri kalan 8 tanesinde ise adrenalin enjeksiyonu ile beraber hemoklips uygulaması yapılmıştı. Hetaer prob koagülasyon ise 4 hastada uygulanmıştı. Hetaer prob 3 hastada primer hemostaz için uygulanırken 1 hastada ise devam eden kanama için uygulanmıştı (Tablo 2).

Mallory-Weiss sendromuna bağlı GIS kanama ile hastaneye başvuran hastalarla endoskopi esnasında MW lezyonu oluşan hastalar arasında aktif kanama, hastanede yatıs ihtiyacı, eritrosit transfüzyonu ihtiyacı, endoskopik tedaviler, hiatal herni varlığı ve MW lezyonunun uzunluğu ve MW lezyonunun mideye uzanımı gibi parametrelerin karşılaştıılmasında iki grup arasında bu parametreler açısından istatistiksel anlamlı bir fark izlenmedi (Tablo 3). 
Tablo 3. Mallory-Weiss senromu nedeni ile hastaneye başvuran hastalar ile endoskopi esnasında Mallory-Weiss Sendromu gelişen hastalar arasında değisskenleri karşılaştırılması

\begin{tabular}{|c|c|c|c|}
\hline Değişken & $\begin{array}{l}\text { MWS'na Bağlı } \\
\text { GIS Kanama ile } \\
\text { Başvuran Hastalar } \\
(22 \text { hasta) }(\%)\end{array}$ & $\begin{array}{l}\text { Endoskopi Esnasında } \\
\text { Oluşan MWS'lu Hastalar } \\
\text { (15 hasta) (\%) }\end{array}$ & $\mathbf{p}$ \\
\hline Aktif kanama bulgusu & $14(63,6)$ & $13(86,7)$ & 0,153 \\
\hline Primer hemostaz & $20(90,9)$ & $15(\% 100)$ & 0,518 \\
\hline Hastaneye yatış & $10(45,5)$ & $3(20)$ & 0,165 \\
\hline Eritrosit transfüzyonu & $2(9,1)$ & $0(0)$ & 0,551 \\
\hline MW lezyonu uzunluğu (ortalama-mm) & $9,4 \pm 3$ & $7 \pm 4,3$ & 0,739 \\
\hline MW lezyonu mideye uzanımı & $6(27,3)$ & $1(6,7)$ & 0,204 \\
\hline Hiatal Herni varlığı & $3(13,6)$ & $2(13,3)$ & 1,00 \\
\hline Hemoklips uygulaması & $14(63,6)$ & $13(86,7)$ & 0,153 \\
\hline Adrenalin enjeksiyonu & $6(27,3)$ & $2(13,3)$ & 0,431 \\
\hline Heater prob & $3(13,6)$ & $1(6,7)$ & 0,633 \\
\hline Kullanılan hemoklips sayısı (ortalama) & $3,1 \pm 1,5$ & $3 \pm 1,7$ & 0,739 \\
\hline
\end{tabular}

MW: Mallory-Weiss. Hemoklips sayısı ve MW lezyon uzunluğunun karşıllaștırılmasında Mann-Whitney U testi, diğer değişkenlerin karșılaștırılmasında ise Fisher's Exact testleri kullanılmıștır.

\section{TARTIŞMA}

Mallory-Weiss sendromu üst GiS kanama nedenleri arasında nispeten nadir görülen, sıklıkla da kanamanın hafif olduğu bir hastalıktır. Mallory-Weiss sendromuna bağlı çoğu kanama kendiliğinden durur ve hastaların çoğunda konservatif medikal tedavi yeterlidir. Endoskopik tedavi ise aktif kanaması olan veya üst GIS endoskopisinde kanama riski yüksek endoskopik işaretleri (yapışık pıhtı, görünür damar) olan hastalarda uygulanmaktadır. Endoskopik tedavi yöntemleri ile çoğu hastada kanama kontrolü sağlanabilinir (5). GiS kanamanın diğer nedenlerine kiyasla mortalitede etkili faktörler ve ilk başvurudaki risk skorlamaları MWS için çok az çalışılmıştır. Bu sendromda mortalitenin diğer GIS kanama nedenlerine kıyasla çok az olduğu kabul edilse de 93 hastanın incelendiği bir çalışmada mortalite \%9,7 sıklıkta izlenmiştir. Bu çalışmada ileri yaş, başvuru esnasındaki düşük hemoglobin seviyesi ve melena varlığı mortalite prediktörleri olarak gösterilmiștir (6). Bizim çalıșmamızda hiçbir hastada mortalite izlenmemiş olup yukarda adı geçen mortalite prediktörlerinin hastalarımızda olmayışı bunda etkili olabilir. MWS ile başvuran hastalarda hangi hastaların hastaneye yatıs ihtiyacı ve yoğun bakım gereksinimi olduğu ile ilgili Lee ve arkadaşlarının yaptıkları çalışmada yüksek Glasgow-Blatchford skoru olan hastaların tekrar kanama oranları ve eritrosit transfüzyonu ihtiyaçları anlamlı olarak daha yüksek izlenmiştir (7).

Mallory-Weiss sendromu tedavisinde farklı bir çok endoskopik tedavi yöntemi kullanılmıştır. Adrenalin enjeksiyonunun tek başına etkinliğini araştıran çalışmalar tartışmalı sonuçlar içerir. Primer hemostazda \%100'e varan başarı oranları bil- dirilse de tekrar kanama riski \%40'lara kadar ulaşabilmektedir $(8,9)$. Bu nedenle günümüzde adrenalin enjeksiyonu tek başına artık kullanılmamaktadır. Bizim serimizde de adrenalin enjeksiyonu hemoklips uygulamasina ilave olarak kullanılmıştır. Hemoklips uygulaması ile ilgili birçok çalışma var olup bu tedavi de etkin ve güvenilir olarak kabul edilir. Huang ve arkadaşlarının yaptıkları prospektif çalışmada hemoklips uygulaması ile primer hemostaz oranı \%100 bulunmuş olup uygulama ile ilgili bir komplikasyona rastlanmamıştır (10). Bizim çalışmamızda da aktif kanama bulgusu olan tüm hastalarda ilk tercih edilen tedavi yöntemi hemoklips uygulaması olmuştur ve primer hemostaz oranı \%92,5 olarak bulunmuştur. Literatürle uyumlu olarak hemoklips uygulaması ile ilgili bir komplikasyona da rastlanılmamıştır. Günümüzde endoskopik band ligasyonu (EBL) MWS tedavisinde yaygın olarak kullanılmaktadır (11). Cho ve arkadaşlarının yaptıkları prospektif bir çalışmada hemoklips uygulaması ile EBL arasında kanama kontrolü arasında fark çımamışıtır ve her iki yöntemin uygulandığı tüm hastalarda primer hemostaz sağlanmıştır (12). Buna karşıllı Lecleire ve arkadaşlarının yaptıkları çalışmada ise EBL, primer hemostazı sağlamada adrenalin enjeksiyonu ile beraber yapılan hemoklips uygulamasından daha başarılı bulunmuştur (13). Sonuç olarak hem hemoklips uygulaması, hem de EBL, MWS tedavisinde etkin ve güvenilir metodlar olup hangisinin kullanılacağına lokal deneyim ve ekipman varllğı ile karar verilebilir.

Mallory-Weis sendromu farklı endikasyonlarla yapılan endoskopik incelemeler esnasında da gelişebilir. Literatürde endoskopik retrograd kolanjiopankreotografi (ERCP), skleroterapi 
ve mukozal rezeksiyon işlemleri esnasında MWS gelişebileceği gibi parenteral sedasyon almayan hastalarda aşırı öğürmeye bağlı olarak da MWS görülebilir. Bizim çalışmamızda hastalarımızın önemli bir kısmında MWS rutin endoskopik incelemeler esnasında oluşmuştu. Kliniğimizde parenteral sedasyonun rutin olarak her hastaya uygulanmaması bunda önemli bir nedendir. Literatürde bu konuyla ilgili yapılan çalışmalar sınırlıdır. Shimoda ve arkadaşlarının yaptıkları çalışmada endoskopi esnasında oluşan MWS'lu hastalar ile MWS'na bağlı GIS kanama ile başvuran hastalar karşılaştırılmış olup gruplar arasinda primer hemostaz, tekrar kanama oranları ve laserasyon uzunluğu arasında fark görülmemiştir. Bununla beraber eritrosit transfüzyonu olan hastalarla MWS'na bağlı GIS kanama ile acile başvuran hastalarda diğer gruba göre anlamlı olarak fazla izlenmiştir (14). Bizim çalışmamızda da her iki grup arasında primer hemostaz ve hastanede yatıs dahil karşılaştırllan parametreler açısından anlamlı farklılık izlenmemiştir. Bununla beraber çalışmamızda primer hemostazın başarısız olduğu 2 hasta MWS’na bağlı GIS kanama ile acile başvuran hastaydı. Hem yukarıda adı geçen çalışma, hem de bizim çalışmamız endoskopi esnasında oluşan MWS'nun nispeten hafif bir klinik seyre sahip olabileceğini düşündürmektedir.

\section{KAYNAKLAR}

1. Gibson JA, Odze RD. Pathology of diseases that cause upper gastrointestinal tract bleeding. Gastrointest Endosc Clin N Am 2011;21:583-96.

2. Yin A, Li Y, Jiang Y, et al. Mallory-Weiss Syndrome: clinical and endoscopic characteristics: Eur J Intern Med 2012;23:e92-6.

3. Bektas M, Korkut E, Idilman R, et al. Treatment of Mallory-Weiss Syndrome using argon plasma coagulation. Endoskopi 2011;19:68-70.

4. Cho YS, Chae HS, Kim HK, et al. Endoscopic band ligation and endoscopic hemoclip placement for patients with Mallory-Weiss syndrome and active bleeding. World J Gastroenterol 2008;14:2080-4.

5. Park $\mathrm{CH}$, Min SW, Sohn YH, et al. A prospective, randomized trial of endoscopic band ligation vs epinephrine injection for actively bleeding Mallory-Weiss syndrome. Gastrointest Endosc 2004;60:22-7.

6. Ljubičić N, Budimir I, Pavič Tet, al. Mortality in high-risk patients with bleeding Mallory-Weiss syndrome is similar to that of peptic ulcer bleeding. Results of a prospective database study. Scand J Gastroenterol 2014:49:458-64

7. Lee S, Ahn JY, Jung HY et al. Effective endoscopic treatment of Mallory-Weiss syndrome using Glasgow-Blatchford score and Forrest classification. J Dig Dis 2016;17:676-84.

8. Chung IK, Kim EJ, Hwang KY, et al. Evaluation of endoscopic hemostasis in upper gastrointestinal bleeding related to Mallory-Weiss syndrome. Endoscopy 2002;34:474-9.
Çalışmamızın bazı eksik noktaları vardır. Bunlardan en önemlisi retrospektif dizayn olup bu durum hastaların tüm verilerine (sigara ve alkol alışkanlıkları, kullandıkları antikoagülan ilaçlar gibi) ulaşabilmeyi olanaksız hale getirmiştir. Bu nedenle ilk başvuru esnasında hastaların vital bulguları ve kanama prezentasyon şekli ile ilgili bilgilerimiz kısıtlayıcıdır. Bu eksiklik de üst GIS kanamalar için iyi bilinen risk skorlamalarını hastalarımız için kullanmayı olanaksız hale getirmiştir. Yine MWS için iyi bilinen alkol alımı gibi risk faktörleri de hasta grubumuzda değerlendirilememiştir. Çalışmamızda bütün MWS tanısı olan hastalara endoskopik tedavi gerekir gibi bir izlenim ortaya çıkmış olabilir. Hastanemizin üçüncü basamak tersiyer bir hastane olması dış merkezlerden gönderilen hasta sıklığında artışa yol açmıştır. Bu da kanaması devam eden hastalarla daha çok karşılaşılmasının ve daha fazla endoskopik tedavi uygulanmasının önemli bir nedenidir. Hiatal herninin MWS ile beraberliğinin sık olduğu ile ilgili bilgiler son çalışmalar ile tartışmalı hale gelmiştir. Corral ve arkadaşlarının yaptıkları bir hiatal herni varlığı MWS olan hastalarla kontrol grubu arasında farklllık göstermemiştir (15). Bizim çalışmamızda da bu çalışmayla uyumlu olarak hiatal herni sıklığı MWS olan hastalarda \%13,5 olarak izlenmiştir.

9. Peng YC, Tung CF, Chow WK, et al. Effi- cacy of endoscopic isotonic saline-epinephrine injection for the management of active Mallory-Weiss tears. J Clin Gastroenterol 2001;32:119-22.

10. Huang SP, Wang HP, Lee YC, et al. Endoscopic hemoclip placement and epinephribe injection for Mallory-Weis syndrome with active bleeding. Gastrointest Endosc 2002;55:842-6.

11. Higuchi N, Akahoshi K, Sumida Y et al. Endoscopic band ligation therapy for upper gastrointestinal bleeding related to Mallory-Weiss syndrome. Surg Endosc 2006;20:1431-4.

12. Cho YS, Chae HS, Kim HK, et al. Endoscopic band ligation and endoscopic hemoclip placement for patients with Mallory-Weiss syndrome and active bleeding. World J Gastroenterol 2008;14:2080-4.

13. Lecleire S, Antonietti M, Iwanicki-Caron I, et al. Endoscopic band ligation could decrease recurrent bleeding in Mallory-Weiss syndrome as compared to haemostasis by hemoclips plus epinephrine. Aliment Pharmacol Ther 2009;30:399-405

14. Shimoda R, Iwakiri R, Sakata H, et al. Endoscopic hemostasis with metallic hemoclips for iatrogenic Mallory-Weiss tear caused by endoscopic examination. Dig Endosc 2009;21:20-3.

15. Corral JE, Keihanian T, Kröner PT, et al. Mallory Weiss syndrome is not associated with hiatal hernia: a matched case-control study. Scand J Gastroenterol 2017;52:462-4 